\title{
NOVA LEX MERCATORIA: ORDENAMENTO JURÍDICO SUPRANACIONAL (?) ${ }^{1}$
}

NEW LEX MERCATORIA: SUPRANATIONAL LEGAL SYSTEM (?)

NUOVA LEX MERCATORIA: ORDINAMENTO GIURIDICO SOVRANAZIONALE (?)

Roberto Epifanio Tomaz ${ }^{2}$

Mario João Ferreira Monte ${ }^{3}$

Osvaldo Agripino de Castro Júnior ${ }^{4}$

$1 \quad$ Artigo produzido em estágio supervisionado por meio do Programa Institucional de Bolsas de Doutorado Sanduíche no Exterior - PSDE, bolsista da CAPES - processo n. ${ }^{\circ}$ 18033/12-1, desenvolvido junto a Universidade do Minho, em Braga, Portugal e na Università degli Studi di Perugia, em Perugia, Italia.

2 Doutorando e Mestre pela Universidade do Vale do Itajaí, professor de Direito Empresarial dos cursos de graduação e pós-graduação (lato sensu) em Direito pela Universidade do Vale do Itajaí, onde também coordena os cursos de pós-graduação em Direito Empresarial e dos Negócios e em Direito Previdenciário e do Trabalho; atua também como advogado.

3 Professor Doutor da Universidade do Minho, em Braga, Portugal, onde também exerce o cargo de Diretor da Escola de Direito. Professor do Programa de Doutorado em Ciência Jurídica da Universidade do Vale do Itajaí. Coorientador do Programa Institucional de Bolsas de Doutorado Sanduíche no Exterior - PSDE, do bolsista da CAPES - processo n. ${ }^{\circ}$ 18033/12-1.

4 Pós-Doutor pela KSG, Harvard University, Professor Titular do Programa de Mestrado e Doutorado em Ciência Jurídica da UNIVALI, Advogado inscrito na OAB/SC e RJ (www.jharoldoagripino.com.br), Consultor e Parecerista em Direito Marítimo, Portuário, Aduaneiro e Regulatório, Árbitro do CMAJ e Expert Witness em Arbitragens, Orientador do Programa Institucional de Bolsas de Doutorado Sanduíche no Exterior - PSDE, do bolsista da CAPES - processo n. ${ }^{\circ}$ 18033/12-1. 
Resumo: O presente artigo tem como objeto de análise a condição dada a lex mercatoria como possível ordenamento jurídico supranacional. O seu objetivo é avaliar o conceito da lex mercatoria, originada na Idade Média como regras eminentemente profissionais aplicadas à classe dos comerciantes, e revitalizado no século $X X$, principalmente após a década de 60 , como uma possível resposta aos desafios atuais do comércio internacional na chamada era da globalização. Sua aplicação como ordem jurídica supranacional é questionada seja por não preencher pressupostos que poderiam configurar um sistema jurídico, seja, ainda que se almeje um ordenamento jurídico supranacional, por não se admitir um ordenamento jurídico supranacional que não respeite o princípio democrático em sua formação. O método utilizado na fase de investigação foi o indutivo; no tratamento dos dados, foi o cartesiano, e no relato dos resultados que se encontra no presente artigo, a base lógica e é também indutiva; a abordagem é descritiva, com aportes analíticos e prescritivos. Como suporte à operação dos métodos, foram empregadas as técnicas do referente, da categoria, do conceito operacional e da pesquisa bibliográfica e documental, esta última, pela via eletrônica.

Palavras chave: Lex mercatoria. Ordem jurídica supranacional.

Abstract: The object of analysis of this article is the condition given to the lex mercatoria as a possible supranational legal system. It objective is to evaluate the concept of lex mercatoria, which originated in the Middle Ages, as eminently professional rules applied to the merchant class, and was revitalized in the twentieth century, especially after the 1960 s, as a possible response to the current challenges of international trade in so-called era of globalization. Its application as a supranational legal system is questioned, whether because it does not fill premises that could form a legal system, or because the goal is a supranational legal system, by not admitting a supranational legal system that does not respect the democratic principle in its formation. The inductive method was used for the 
research; the Cartesian method was used for the data analysis; and the report of these results in this article used a logical and inductive base. The approach is descriptive, with analytical and descriptive tools. As support for the operation of the methods, the techniques of referent, category, operational concept and bibliographic and documentary research were used, the latter, by electronic means.

Keywords: Lex mercatoria. Supranational legal system.

Riassunto: Il presente articolo ha per oggetto l'analisi della condizione data alla lex mercatoria come un possibile ordinamento giuridico sovranazionale. Lo scopo è quello di valutare il concetto di lex mercatoria che ha avuto origine nel Medioevo come regole eminentemente professionali applicate alla classe dei mercanti e rivitalizzata nel XX secolo, sopratutto dopo gli anni '60, come una possibile risposta alle sfide attuali del commercio internazionale nella cosiddetta era della globalizzazione. La sua applicazione come ordine giuridico sovranazionale viene messa in discussione sia per il fatto di non soddisfare i presupposti che potrebbero configurare un sistema giuridico, sia perché, anche se è auspicabile un ordinamento giuridico sovranazionale, non è ammissibile un ordinamento giuridico sovranazionale che non rispetti il principio democratico nella sua formazione. Il metodo utilizzato nella ricerca è stato quello induttivo, e nell'analisi dei dati quello cartesiano, per il reporting dei risultati presenti in questo articolo la base è logica e anche induttiva; l'approccio è descrittivo, con contributi analitici e prescrittivi. Come sostegno al metodo utilizzato sono state impiegate le tecniche del referente, della categoria, del concetto operativo e della ricerca bibliografica e documentale, quest'ultima per via elettronica.

Parole chiave: Lex mercatoria. Ordine giuridico sovranazionale. 


\section{INTRODUÇÃO}

o conjunto de regras e práticas originadas e estabelecidas pela
classe comerciante organizada nas chamadas corporações de ofício
(ou corporações mercantis) a partir do século XII, nominou-se lex mercatoria ou ius mercatorum.

Sob a égide do ius mercatorum as práticas comerciais, independente de território, eram difundidas e aceitas, sua violação implicava a exclusão do comerciante infrator do respectivo mercado que era plenamente hábil para promover sua regulação.

A lex mercatoria, por meio das corporações, permitiu a estrema difusão do comércio e ainda mais o fortalecimento da classe mercantil medieval que acabou por apoiar a formação do Estado-nacional frente ao poderio centralizador dos senhores feudais. Foi, entretanto, o fortalecimento deste último que levou, por sua vez, a decadência da era corporativa, vez que, após o século XIV, o Estado passou a assumir o papel que até então era exercido pelo ius mercatorum.

O século $X X$, entretanto, por uma série de fatores ligados ao fenômeno chamado globalização, faz ressurgir os desafios de um comércio internacional livre das barreiras criadas, principalmente, pelos Estados-nações, por meio de seus ordenamentos, trazendo de volta a ideia de uma nova lex mercatoria que possa gerir as relações comerciais, configurando uma autêntica ordem jurídica supranacional que possa, inclusive, derrogar, eventualmente, normas jurídicas nacionais que lhe sejam desfavoráveis.

Uma nova lex mercatoria, capaz de tutelar sozinha de forma uniforme e adequada os novos desafios do comércio internacional, leva consequentemente a indagação se um sistema de normas corporativo poderia ser considerado um sistema jurídico e, com a eventual confirmação, se este sistema normativo poderia, efetivamente, estar acima dos sistemas jurídicos nacionais, ou seja, poderia se configurar num sistema jurídico supranacional.

Assim sendo, o presente artigo tem como objeto a compreensão da condição 
arbitrada à chamada nova lex mercatoria como possível ordenamento jurídico supranacional.

O objetivo é avaliar o conceito da lex mercatoria, originada na Idade Média como regras eminentemente profissionais aplicadas à classe dos comerciantes, e revitalizado no século XX e, por fim, estabelecer critérios para uma análise sobre a possível configuração da lex mercatoria como um sistema jurídico supranacional.

O método utilizado na fase de investigação foi o indutivo ${ }^{5}$, no tratamento dos dados foi o cartesiano ${ }^{6}$, e no relato dos resultados que se consiste neste ensaio, a base lógica é, também, indutiva.

As técnicas empregadas foram a do referente ${ }^{7}$, da categoria $^{8}$, do conceito operacional $^{9}$ e da pesquisa bibliográfica ${ }^{10}$ e documental, esta última, pela via eletrônica.

\section{LEX MERCATORIA, ANTIGO CONCEITO REVITALIZADO}

Com o termo "lex mercatoria" ou outras expressões mais ou menos equivalentes, como "direito autônomo do comércio internacional", "autonomous law of

5 O método indutivo consiste em "[...] pesquisar e identificar as partes de um fenômeno e colecioná-las de modo a ter uma percepção ou conclusão geral [...]". PASOLD, Cesar Luiz. Metodologia da Pesquisa Jurídica: Teoria e Prática. 12. ed. rev. São Paulo: Conceito Editorial, 2011. p. 86.

6 O método cartesiano, segundo Cesar Luiz Pasold, pode ser sintetizado em quatro regras "[...] 1. duvidar; 2. decompor; 3. ordenar; 4. classificar e revisar. Em seguida, realizar o Juízo de Valor.". PASOLD, Cesar Luiz. Metodologia da Pesquisa Jurídica: Teoria e Prática. 12. ed. rev. São Paulo: Conceito Editorial, 2011. p. 204. Categorias grifadas em maiúscula no original.

7 Denomina-se referente "[...] a explicitação prévia do(s) motivo(s), do(s) objetivo(s) e do produto desejado, delimitando o alcance temático e de abordagem para a atividade intelectual, especialmente para uma pesquisa." PASOLD, Cesar Luiz. Metodologia da Pesquisa Jurídica: Teoria e Prática. 12. ed. rev. São Paulo: Conceito Editorial, 2011. p. 54. Negritos no original.

8 Entende-se por categoria a "[...] palavra ou expressão estratégica à elaboração e/ou à expressão de uma idéia." PASOLD, Cesar Luiz. Metodologia da Pesquisa Jurídica: Teoria e Prática. 12. ed. rev. São Paulo: Conceito Editorial, 2011. p. 25. Negritos no original.

9 Por conceito operacional entende-se a "[...] definição estabelecida ou proposta para uma palavra ou expressão, com o propósito de que tal definição seja aceita para os efeitos das idéias expostas". PASOLD, Cesar Luiz. Metodologia da Pesquisa Jurídica: Teoria e Prática. 12 ed. rev. São Paulo: Conceito Editorial, 2011. p. 198.

10 Pesquisa bibliográfica é a "Técnica de investigação em livros, repertórios jurisprudenciais e coletâneas legais". PASOLD, Cesar Luiz. Metodologia da Pesquisa Jurídica: Teoria e Prática. 12 ed. rev. São Paulo: Conceito Editorial, 2011. p. 207. 
international trade", "new law merchant", "autonomes Recht des Welthandels", etc., se costuma designar o conjunto de princípios e regras que se estabeleceram na prática do comércio internacional e que tem sido chamado para garantir a regulação das relações de negócios individuais e que, possivelmente, são mais funcionais do que os direitos nacionais tradicionais ${ }^{11}$.

No decorrer das épocas, inúmeros têm sido os esforços no sentido de padronizar as práticas comerciais mundiais. Uma sociedade autônoma de vendedores e compradores do comércio internacional, pela reiterada prática de atos contratuais, aliada a uma vontade específica para a criação de regras próprias à sua atividade, por sua vez, acabaria por gerar um direito distinto dos direitos nacionais, a que se denominaria de lex mercatoria, com status de autêntico sistema jurídico distinto do tradicional costume comercial internacional.

Segundo Huck ${ }^{12}$, um direito dos mercadores é alvo tão antigo quanto o próprio comércio. Traços de um sistema análogo podem ser encontrados já no ano 300 a.C., com a Lei do Mar de Rodes, adotada por gregos e romanos e, posteriormente, introduzida no restante da Europa. No curso do tempo, várias manifestações jurídicas no mesmo sentido são detectadas, tais como as regras de direito marítimo desenvolvidas pelo Imperador Basílio I, no século IX; as tábuas de Amalfi, editadas no século XII na Corte de Oleron, uma ilha atlântica da costa francesa; as leis de Wisby, que desde 1350 regulavam o comércio no mar Báltico; o Consulado do Mar, ainda no século XIV, uma coletânea de costumes do comércio marítimo, reunida pela Corte Consular de Barcelona e aceita em praticamente todos os centros comerciais marítimos da Europa.

Entretanto, malgrado a importância daquilo que se poderia chamar de comércio internacional já no período da Alta Idade Antiga, das quais civilizações como a dos fenícios, dos gregos e da Roma Antiga se destacavam como fontes históricas no processo de desenvolvimento do comércio internacional, é apenas na Idade Média que se assinala o período de formação do que atualmente se

11 BONELL, Michael Joachim. Lex mercatoria. Digesto Discipline Privatistiche. Sezione Commerciale IX. Torino: UTET, 1993. p. 11.

12 HUCK, Hermes Marcelo. Sentença estrangeira e "Lex Mercatoria": horizontes do coméercio internacional. São Paulo: Saraiva, 1994, p. 104. 
conhece como Direito Comercial ${ }^{13}$.

É neste período que o comércio e a indústria, sob o influxo das ideias do Cristianismo, travaram, por bem de sua liberdade e desenvolvimento, a renhida luta contra as velhas instituições políticas e contra a inflexibilidade, a rigidez e a dureza das regras do direito romano. Assim, à medida que o comércio impulsionava as transações e desenvolvia o crédito, começaram a aparecer nas ditas Repúblicas da Itália, como Veneza, Gênova, Pisa, Florença, etc., usos e costumes seguidos do trato dos negócios que veio a caracterizar a primeira manifestação jurídica do exercício do comércio ${ }^{14}$.

Stoecker ${ }^{15}$ lembra que,

Parallel to this development, a large body of laws governing overland trade evolved in the Middle Ages. The merchants travelling to the different markets, fairs and sea-ports to trade their goods had their own laws, and legal systems which were distinct from the laws applicable in their respective States. The commercial customs that developed were confirmed and given legal definition by the mercantile courts which were made up generally of members of the merchant class, their election dependent upon their experience and knowledge.

Pode-se apontar a queda do Império Romano, parte ocidental, que cominou numa Europa presa na anarquia, como a circunstância propícia que levou, com o tempo, ao desenvolvimento da organização da classe dos comerciantes. A falta de um poder político em condições de manter a paz interna e a realização do direito fez com que, com o tempo, se constituíssem corporações de classe, entre elas as chamadas corporações de mercadores que objetivavam a proteção e a assistência dos comerciantes, tanto no interior como no exterior. Cada corporação, ensina Strenger ${ }^{16}$, formava como que um pequeno Estado, dotado de um poder legislativo e de um poder judiciário; tinha patrimônio próprio, constituído pelas

13 STRENGER, Irineu. Direito do Comércio Internacional e Lex Mercatoria. São Paulo: LTR, 2009, p.55, 57.

14 STRENGER, Irineu. Direito do Comércio Internacional e Lex Mercatoria. São Paulo: LTR, 2009, p.57, 58.

15 STOECKER, C. W. The Lex Mercatoria: to what extent does it exist. Journal of International Arbitration, Vol. 7, n. 1, 1990, p. 102.

16 STRENGER, Irineu. Direito do Comércio Internacional e Lex Mercatoria. São Paulo: LTR, 2009, p.58. 
contribuições dos associados e por taxas extraordinárias e pedágios; participavam, mediante seus representantes e oficiais, nos Conselhos da Comuna; vigiavam sobre a guerra e a paz, sobre as represálias; formavam as próprias leis e estatutos e, mediante jurisdição própria, cuidavam da sua observância.

Este é o cenário da gênese da chamada lex mercatoria que em resposta aos direitos feudais e em contraposição ao direito romano, plenos de privilégios, entravavam as relações de comércio, surge como ordenamento a reger as relações entre os comerciantes, de modo uniforme, por meio da aplicação obrigatória dos usos e dos costumes comerciais.

Destarte, sob a égide das ius mercatorum, as práticas comerciais eram difundidas e aceitas, sua violação implicava a exclusão do comerciante infrator do respectivo mercado que eram plenamente hábeis para promover a regulação e a evolução deste seguimento.

A época áurea da lex mercatoria, regras corporativas mais ou menos uniformes e aceitas e aplicadas independentemente dos territórios, faz fortalecer ainda mais o comércio que se expande por todo o mundo conhecido da época, auxiliado pela promoção de grandes e audazes expedições marítimas.

As sociedades corporativas apenas começam a entrar em decadência após o século XIV, quando o Estado-nacional começa a ganhar força, assumindo o papel até então exercido pelo ius mercatorum dos comerciantes medievais, fenômeno que leva a consolidação do Estado nacional moderno ${ }^{17}$.

Segundo Strenger ${ }^{18}$, muito embora a lex mercatoria tenha possuído grande importância na Idade Média, caiu em desuso com a fase das codificações iniciada com o Código de Napoleão:

Essa manifestação codificadora, naturalmente, contribuía para o nascimento de códigos territoriais que se seguiram e enfraqueceram a atividade livre dos comerciantes, contrariando seus interesses na parte relativa às operações internacionais; os séculos XVIII e XIX caracterizamse pela incorporação das praticas e usos comerciais em ordenamentos

17 CATALAN, Marcos Jorge; BUSSATTA, Eduardo Luiz. A Lex Mercatoria. Revista Jurídica Consulex, Ano VII, n. 166, 2003, p. 56.

18 STRENGER, Irineu. Direito do Comércio Internacional e Lex Mercatoria. São Paulo: LTR, 2009, p. 61. 
internos, de onde se deduz o entendimento de que as leis nacionais seriam as únicas a governar as relações internacionais, com motivações que variavam de Estado para Estado.

É, portanto, de forma irônica de que a estrutura proporcionada pela lex mercatoria que de início contribui para formação dos Estados-nacionais, com a estruturação destes a partir das codificações deixou de ser apenas os "problemas do comércio" para passar a ser submetidos às jurisdições domésticas e não mais uma ordem jurídica independente, o que tornou bastante limitada a extensão e o caráter do comércio internacional.

O comércio passa ser questão de interesse do Estado que encontra nele não só fonte de manutenção, tributação, mas fator preponderante para difundir a propagação e de "distribuição" de riquezas por meio da produção industrial e a contratação de mão de obra e as diversas outras atividades que as derivam.

O século XX e o processo de globalização ${ }^{19}$, acirrado, principalmente, segundo $\mathrm{Cruz}^{20}$, após o fim da disputa ideológica entre capitalismo e socialismo, caracterizado pela forte e crescente internacionalização do comércio, traz de volta os desafios e as tentativas de manter correlação com as necessidades circunscritas à comunidade mercantil ${ }^{21}$.

Conforme Lando 22 , o vazio legislativo e o caráter esparso da jurisprudência não puderam fornecer o quadro necessário para acompanhar o desenvolvimento das relações comerciais internacionais depois da Primeira Guerra Mundial. Estas circunstâncias, somadas à diversidade dos sistemas legais e à participação dos Estados nos atos de comércio, têm convencido juristas e comerciantes de que as leis nacionais interferem negativamente no crescimento global do comércio

19 Para SANTOS, Boaventura de Souza, a globalização é um fenômeno multifacetado com dimensões econômicas, sociais, políticas, culturais, religiosas e jurídicas interligadas de modo complexo. In SANTOS, Boaventura de Sousa (org.). Globalização: Fatalidade ou Utopia? 3. ed. Porto: Afrontamento, 2005. p. 32.

20 CRUZ, Paulo Marcio. Da Soberania a Transnacionalidade: Democracia, Direito e Estado no Século XXI. Itajaí, UNIVALI Editora, 2011, p. 15, 105.

21 TOMAZ, Roberto Epifanio. Governança Transnacional. Revista do Direito, UNISC, Santa Cruz do Sul/RG, no. 40, Agosto/Outubro, 142-163, 2013. Disponível em: < http://www. http://online.unisc.br/seer/index.php/direito/article/view/3710/2887 >. Acesso em: 22 de março de 2014, p 145.

22 LANDO, Ole. The Law Applicable to the Merits of the Dispute. Essays on International Commercial Arbitration. London: Petar Sarcevic, Graham \& Trotman/Martins Mijhoff, 1989, p. 143. 
e de que há necessidade de desenvolver regras que possam ser aplicadas indistintamente, seja onde for que ocorra uma transação de comércio e força reconhecer que uma autonomia comercial que supostamente possa crescer independentemente dos sistemas nacionais desse direito seja a melhor solução para regular o comércio internacional, ou seja, um ressurgimento do que outrora era conhecido como lex mercatoria.

Destarte, a exemplo do ius mercatorum, nascido no século XI e XII na esteira dos costumes comerciais, com jurisdição especial, baseado na autonomia corporativa e sem intervenção do Estado, pretendem-se a concepção e a vigência de uma nova lex mercatoria concebida no final do século XX.

Goldman ${ }^{23}$ é quem lança o que se pode chamar do fundamento doutrinário para uma nova lex mercatoria em artigo publicado em 1964, defendendo-a como um direito positivo distinto e autônomo com fim de regular o comércio internacional, livre das barreiras e das limitações impostas pelos direitos nacionais.

$\mathrm{Na}$ opinião de Guerreiro ${ }^{24}$, ou se adota essa normatividade supranacional que ganha corpo com o título de lex mercatoria, pela razão que ela permite soluções que atendem à necessidade e à conveniência das partes, com eficiência e neutralidade, mas com o risco, sempre presente, da incerteza ou da incalculabilidade quanto ao resultado final da decisão arbitral, ou se permanece sob a égide dos mecanismos tradicionais das regras de conflito, com apelo necessário às legislações nacionais, o que aparentemente tem a seu favor maior certeza do direito aplicável, mas que, em muitas oportunidades, não tem conduzido as partes a soluções razoáveis e equitativas, como seria evidentemente de desejar.

Para Lando ${ }^{25}$,

The parties to an international contract sometimes agree not to have their dispute governed by national law. Instead they submit it to the customs and usages of international trade, to the rules of law which are

23 GOLDMAN, Berthold. Les frontières du droit et lex mercatoria. Archives de Philosophie du Droit. n. 9, 1964, p. 177.

24 GUERREIRO, José Alexandre Tavares. Fundamentos da arbitragem do comercio internacional. São Paulo: Saraiva, 1993, p. 96.

25 LANDO, O. The lex mercatoria in international commercial arbitration. The International and Corporative Law Quarterly, n. 34, 1985, p. 747. 
common to all or most of the States engaged in international trade or to those States which are connected with the dispute. Where such common rules are not ascertainable, the arbitrator applies the rules or chooses the solution which appears to him to be the most appropriate and equitable. In doing so be considers the laws of several legal systems. This judicial process, which is partly an application of legal rules and partly a selective and creative process, is here called application of the lex mercatoria.

Sob estas perspectivas, a ideia de uma nova lex mercatoria se propaga como um sistema de normas nascido da coesão de regras de caráter profissional ou associativo adotadas pelos comerciantes na ordem internacional (ao lado das convenções internacionais que buscam unificar as regras à prática do comércio internacional ${ }^{26}$ e de diversas entidades privadas dedicam-se à uniformização dessas regras, tais como a UNIDROIT ou a Câmara de Comércio Internacional de Paris - CCI), formando uma ordem jurídica supranacional que nega as relações internacionais tradicionais do comércio derivada dos ordenamentos jurídicos internos e atua como um poder normativo independente do direito positivo dos Estados.

Ainda que desejável, a ideia propagada da nova lex mercatoria leva, por conseguinte, a indagação de que se um sistema de regras corporativo poderia configurar um sistema jurídico e, por conseguinte, com a eventual confirmação, se este sistema normativo poderia efetivamente estar acima dos sistemas jurídicos nacionais estabelecidos pelos Estados-nações, capaz de sozinho tutelar de forma adequada os atuais desafios do comércio internacional.

Malgrado as discussões já defendidas por autores, que poderiam gerar diversas formas de abordagem e perspectivas para esta análise, a presente pesquisa toma por base a avaliação do preenchimento de requisitos pela nova lex mercatoria que possam configurar como um sistema jurídico supranacional, reflexões tecidas no próximo item.

\section{LEX MERCATORIA E ORDEM JURÍDICA SUPRANACIONAL}

O conceito de uma lex mercatoria, um comércio internacional desvinculado das limitações impostas pelos direitos nacionais, exerce intenso fascínio seja sobre o 26 As Convenções de Haia (1954) e de Viena (1980), definindo normas uniformes para a compra e venda internacional de mercadorias, representam claros exemplos. 
jurista ou sobre a classe dos comerciantes internacionais. A privatização das regras desse comércio, possivelmente, traria inegáveis vantagens de ordem prática e, a partir dessa perspectiva, não há que se descuidar ou abandonar as hipóteses que orientam para a uniformização do direito do comércio internacional. Mas este trabalho, nas palavras de Huck ${ }^{27}$, "deve ser desenvolvido sem delírios ou fantasias".

Malgrado, desde os fins dos anos 60, fala acerca de uma nova lex mercatoria que teria o condão de flexibilizar as rígidas regras do direito legislado e de construir "um conjunto de regras e de princípios consagrados como normas jurídicas no comércio internacional", contudo, ainda que um sistema unificado de normas possa ser almejado, a lex mercatoria como um ordenamento profissional, acima dos direitos nacionais, aplicável exclusivamente ao comércio internacional, tem, por sua vez, provocado divergências relativas à sua abrangência, efetividade e aplicação, bem como se esta poderia configurar um sistema jurídico supranacional capaz de sozinho tutelar os atuais desafios do comércio internacional.

Para Costa ${ }^{28}$, orenascimento do ius mercatorum não tem o efeito deeclipsara questão das fontes normativas como nos contratos internacionais de compra e venda, sabendose que ainda hoje inúmeros sistemas admitem os costumes como fonte legítima de produção normativa, assim, o que se tem, na verdade, é uma mescla de modelos de fontes, de um lado o modelo da prática, traduzida na expressão "usos do comércio internacional", origem da lex mercatoria, e de outro o modelo da regulamentação de ordem convencional. Em ambos, entretanto, convivem os princípios que, em geral, passam do plano da prática para o plano da regulamentação jurídica convencional, sendo, desta forma, recolhidos ou recebidos pelo direito escrito.

Segundo Lagarde ${ }^{29}$, a originalidade da lex mercatoria é a de ser um direito espontâneo, criado por meio das societas mercatorum e é, portanto, fora das origens estatais que é preciso procurar as suas interpretações.

27 HUCK, Hermes Marcelo. Sentença estrangeira e "Lex Mercatoria": horizontes do comercio internacional. São Paulo: Saraiva, 1994, p. 119.

28 COSTA, Judith Martins. Os Princípios Informadores do Contrato de Compra e Venda Internacional na Convenção de Viena de 1980. Universidade Federal Fluminense. Disponível em: <http://www.uff.br/cisgbrasil/costa.html\#top>. Acesso em: 22 de março de 2014.

29 LAGARDE, Paul. Approche Critique de la Lex Mercatoria. In: Le droits dês relations économiques internationais. Études offertes à Berthold Goldman. Paris: Librairies Techniques, 1987, p. 135. 
Já para Lafer ${ }^{30}$, essa nova lex mercatoria acaba por esbarrar no intervencionismo econômico dos Direitos Públicos internos dos Estados que, em última análise, controlam o acesso de empresas multinacionais aos seus territórios, configurandose, nesse processo, uma situação tensa entre a ambição de objetivo universal das experiências econômicas e a territorialidade do Estado-nação.

Nas palavras de Huck ${ }^{31}$, "Estado e lex mercatoria são conceitos (e realidades político-jurídicas) quase excludentes, e certamente conflitantes". O que remete novamente à reflexão da ironia que levou as sociedades corporativas de comerciantes à consolidação do Estado-moderno e à atual dificuldade do atual Estado-nacional em aceitar uma atual lex mercatoria que o ignore.

Para Guerreiro ${ }^{32}$

O Estado, enquanto titular do poder normativo e fonte de regras jurisdicionais, configura uma realidade, mas essa comunidade de comerciantes o agentes do comércio internacional configura outra realidade, não conflitante com a primeira, por se referir a interesses diferentes, mas igualmente podendo ser capaz de ser dotada de poder normativo distinto, e podendo se converter, por igual forma, em fonte de regras jurídicas.

Percebe-se, portanto, que as divergências de opiniões exige o tratamento da questão com o cuidado metodológico técnico-jurídico que se disponha a dar uma resposta aos desafios da atual lex mercatoria em servir como um direito supranacional, aplicado às relações comerciais.

Desta forma, observados os limites operacionais da atual pesquisa, destacase, para fins de análise da questão problema aqui abordada, o preenchimento de requisitos que possam configurar um sistema jurídico supranacional, adotandose, para tanto, a lição de Huck ${ }^{33}$ que pondera ser necessária para a existência de um direito supranacional, inicialmente, a presença de um corpo social capaz de

30 LAFER, Celso. In CATALAN, Marcos Jorge; BUSSATTA, Eduardo Luiz. A Lex Mercatoria. Revista Jurídica Consulex, Ano VII, n. 166, 2003, p. 56.

31 HUCK, Hermes Marcelo. Sentença estrangeira e "Lex Mercatoria": horizontes do comercio internacional. São Paulo: Saraiva, 1994, p. 104.

32 GUERREIRO, José Alexandre Tavares. Fundamentos da arbitragem do comércio internacional. São Paulo: Saraiva, 1993. p. 71.

33 HUCK, Hermes Marcelo. Sentença estrangeira e "Lex Mercatoria": horizontes do comercio internacional. São Paulo: Saraiva, 1994, p. 115. 
construir um sistema jurídico (no caso, para a lex mercatoria, tal corpo seria a sociedade de comerciantes); referido sistema, por sua vez, há de ter autonomia e ostentar uma incontestável independência das normas dos direitos positivos estatais; e, por fim, ser autocontido, inclusive no tocante às sanções que vier a aplicar (e principalmente nelas), dispondo coercitivamente para suas decisões.

Para Goldman ${ }^{34}$, a lex mercatoria, respondia quase integralmente aos requisitos defendendo que, inicialmente, as normas prescritas pela lex mercatoria originamse numa autoridade profissional e não estatal, como aquelas que ditam os contratotipos e patrocinam a arbitragem (foro ideal para a implementação desse sistema jurídico). Outrossim, prescreve que este sistema jurídico do comércio internacional conta com uma coação que seria exercida, num primeiro momento, por meio da pressão moral da classe dos comerciantes, seguida por penalidades comerciais, pela publicidade, ou, finalmente, pelo próprio Estado.

Entretanto, na lição de Lagarde ${ }^{35}$ observa-se que a lex mercatoria não admite a condição de ordem jurídica ou sistema jurídico por lhe faltar organização suficiente e coesão social à sociedade dos comerciantes de onde se origina; para o jurista francês, não há apenas uma única sociedade organizada de mercadores, mas várias delas.

$K \mathrm{hhn}^{36}$, não obstante ser defensor da lex mercatoria, reconhece que é necessário que os operadores do mercado internacional constituam um meio suficientemente homogêneo para que a solidariedade profissional se faça sentir para que fiquem claras as necessidades jurídicas coerentes e adequadas.

Somam-se a este desafio a extensão e a diversificação atual do mercado mundial, em que a multiplicidade de costumes e culturas atingem diretamente as formas de fazer comércio, tornando-se uma barreira à uniformização e à aceitação da atual lex mercatoria, tarefa esta inquestionavelmente mais simples na Idade Média, cujas distâncias geográficas, culturais e costumeiras eram bastante menores.

34 GOLDMAN, Berthold. Les frontières du droit et lex mercatoria. Archives de Philosophie du Droit. n. 9, 1964, p. 192.

35 LAGARDE, Paul. Approche Critique de la Lex Mercatoria. In Le droits dês relations économiques internationais. Études offertes à Berthold Goldman. Paris: Librairies Techniques, 1987, p. 125.

36 KAHN, Philipe. Lex mercatoria et pratique des contrats internationaux: I'expérience français. In Le Contrat Économique International. Bruxelles-Paris, 1975, p. 173. 
Parece, portanto, faltar o primeiro dos requisitos à lex mercatoria para que venha ser aceita como um sistema ordenado a ser reconhecido como direito supranacional, malgrado haver esforços tanto profissionais quanto institucionais nesta área como mencionados anteriormente. A esta ausência de um corpo de normas uniforme aceito em todas as áreas do comércio internacional, não obstante haverem exemplos pontuais de regras internacionalmente aceitas ${ }^{37}$, soma-se a ausência, de uma forma geral, às regras advindas da lex mercatoria, de sua completa autonomia dos Estados-nacionais, bem como da possibilidade de impor sansão.

Segundo Kassis ${ }^{38}$, as regras do comércio internacional encontram-se sempre vinculadas a um direito nacional, paralelamente a esta vinculação deve haver uma aceitação dos princípios desse conjunto de regras pelos próprios direitos nacionais, pois, caso contrário, a ordem pública soberana de cada Estado há de barrar a aplicação direta ou indireta desse mesmo conjunto de princípios perante o referido direito nacional.

Neste sentido, Huck ${ }^{39}$ leciona que a atual lex mercatoria difere em muito da aplicada na Idade Média, vez que esta não esbarrava nas barreiras de Judiciários estatais, pois sua aplicação ocorria em tribunais próprios dos comerciantes, e destes tribunais jamais extravasava. Os direitos nacionais, frutos das políticas econômicas e sociais (e, por consequência, jurídicas) de cada grupo nacional, representam, atualmente, uma barreira ao sofisticado conceito de eficiência pragmática, tão almejado entre os responsáveis pelo comércio internacional, quando importa apenas o resultado final obtido e insofismavelmente dimensionado pela regra do lucro.

A supressão total dos direitos nacionais, ou mesmo sua submissão a uma internacionalizada lex mercatoria, com a consequente eliminação das razões de ordem política e social, implicaria fatalmente o predomínio exclusivo das leis do mercado. A especulação, nessa hipótese, seria inevitável ${ }^{40}$.

37 Os Incoterms, criados em 1936 pela Câmara de Comércio Internacional, são exemplos de referências comerciais padronizadas, definindo direitos e deveres assumidos pelo importador e pelo exportador nas operações do comércio internacional.

38 KASSIS, Antoine. Problèmes de Base de I'Arbitrage en Droit Comparé et en Droit International. Paris: LGDI, 1987, p. 578.

39 HUCK, Hermes Marcelo. Sentença estrangeira e "Lex Mercatoria": horizontes do comercio internacional. São Paulo: Saraiva, 1994, p. 121.

40 HUCK, Hermes Marcelo. Sentença estrangeira e "Lex Mercatoria": horizontes do co- 
Para Lagarde ${ }^{41}$, ainda que no campo da arbitragem internacional, no qual se têm permitido amplas concessões à aplicação de direito transnacional, não se admite a aplicação pelos árbitros da lex mercatoria, salvo expressa autorização das partes. À falta desta indicação, deverão os árbitros recorrer a um direito nacional para solução da pendência arbitrada.

Destarte, sejam os costumes comerciais internacionais ou os usos do comércio international para ser efetivamente aplicadas devem ser acolhidas perante o ordenamento jurídico interno sempre que não contrários à lei ${ }^{42}$.

A análise dos requisitos para que a lex mercatoria se constitua num sistema jurídico supranacional autônomo ainda se agrava quando, para além da autonomia, se questiona o grau de sansão de que são dotadas as regras que a compõem.

Segundo Stoecker ${ }^{43}$, a ampla e irrestrita aceitação de uma lex mercatoria por parte de tribunais estatais caracterizaria um forte impacto nos conceitos vigentes, na medida em que implicaria a concessão de parte da soberania do Estado em favor das mãos invisíveis de uma inconstante comunidade de comerciantes, que faz a lei de acordo com suas conveniências e necessidades.

Para Huck, ${ }^{44}$ quando a coação do sistema mercatório falta, falha ou é insuficiente, não resta alternativa que não o vincular ao direito estatal, de onde sempre quis fugir, opinião que, mesmo minimizada, também é emitida por Goldman ${ }^{45}$, para quem, em alguns casos, a sentença arbitral fundamentada por normas próprias do direito do comércio internacional (ou seja, lex mercatoria) não possa ser executada senão com a intervenção da força do Estado que não deve Ihe negar exequibilidade senão por motivo de força maior.

mercio internacional. São Paulo: Saraiva, 1994, p. 121.

41 LAGARDE, Paul. Approche Critique de la Lex Mercatoria. In Le droits dês relations èconomiques internationais. Études offertes à Berthold Goldman. Paris: Librairies Techniques, 1987, p. 125.

42 PINHEIRO, Luís de Lima. Direito Comercial Internacional - O Direito Privado da Globalização Econômica. Lisboa: Colibri, 2005, p. 166.

43 STOECKER, Christoph W. O. The lex mercatoria: to what extent does it exist? Journal of International Arbitration, v. 7, n. 1, 1990, p. 108.

44 HUCK, Hermes Marcelo. Sentença estrangeira e "Lex Mercatoria": horizontes do comercio internacional. São Paulo: Saraiva, 1994, p. 104.

45 GOLDMAN, Berthold. Les frontières du droit et lex mercatoria. Archives de Philosophie du Droit. n. 9, 1964, p. 192. 
Sendo assim, Huck ${ }^{46}$ entende ser fundamental que os Estados, por meio de seu poder jurisdicional ou legislativo, reconheçam a lex mercatoria, pois, caso contrário, não haverá forma de impor a efetividade da mesma dentro dos limites territoriais do Estado, e tal construção de normas se tornará absolutamente ineficaz, "simples jogo ou brinquedo nas mãos de uma poderosa classe internacional". De muito pouco valerá um contrato regido por um direito supranacional se não for aceito e reconhecido pelo tribunal estatal em que se busca a sua execução ou mesmo uma interpretação. Se a execução for negada no exterior, em que sua eficácia seria necessária, se neste Estado estrangeiro o Tribunal entender que lhe falta algum fundamento em direito nacional.

Desta forma, apesar da tendência crescente dentro do direito comercial internacional e certamente na própria sociedade de comerciantes no sentido da admissão de um conjunto de normas ou mesmo de um sistema jurídico supranacional, não se pode confundir esta tendência com a efetiva existência desse sistema, sob pena de se tornar o estudo do direito do comércio internacional um mero exercício de vontades e desejos, afastado da realidade comercial, sua base fundamental ${ }^{47}$.

Segundo Huck ${ }^{48}$,

... a concepção de direito da lex mercatoria é inoportuna, enquanto nela se pretenda ver um sistema jurídico supranacional, pois vem marcada por uma ideologia que almeja ver afastada qualquer intervenção dos direitos nacionais sobre as relações do comércio internacional. Pretender ignorar o papel fundamental desempenhado pelo Estado nas relações econômicas, financeiras e comerciais internacionais é, no mínimo, esconder a verdade. Sem qualquer defesa do intervencionismo, não se pode negar que o Estado deva exercer função essencial nas relações do comércio internacional, buscando minimizar as distorções que o flagrante desequilíbrio econômico entre as nações injeta nas relações comerciais.

46 HUCK, Hermes Marcelo. Sentença estrangeira e "Lex Mercatoria": horizontes do comércio internacional. São Paulo: Saraiva, 1994, p. 108.

47 HUCK, Hermes Marcelo. Sentença estrangeira e "Lex Mercatoria": horizontes do comércio internacional. São Paulo: Saraiva, 1994, p. 118.

48 HUCK, Hermes Marcelo. Sentença estrangeira e "Lex Mercatoria": horizontes do comércio internacional. São Paulo: Saraiva, 1994, p. 119. 
O ideal de um sistema jurídico supranacional que consiga governar sozinho às relações do comércio internacional deve, por sua vez, ser alimentado num quadro de realismo, pois seria inaceitável um acolhimento de uma ordem jurídica supranacional que não levasse em consideração elementos democráticos.

Nas palavras de Cruz ${ }^{49}$, "o mundo no séculoXXIjá não crêmais numa legitimidade que não seja democrática", portanto uma possível e nova construção jurídica transnacional que pretenda ser aceira como ordem supranacional deve incluir não apenas a classe dos comerciantes internacionais, mas a sociedade mundial cada vez mais globalizada e organizada, representada seja por organizações transnacionais, seja pelo Estado-nacional ${ }^{50}$

\section{CONSIDERAÇÔES FINAIS}

A lex mercatoria surgida na alta Idade Média como um direito corporativo resultado da desorganização social e política provocada na Europa a partir da queda do Império Romano e da organização, a partir dos anos, dos comerciantes que se levantaram em defesa e fortalecimento de seus negócios, representou fundamental avanço em face de quebra da dominação feudal e o apoio ao surgimento do Estado como organização social.

Ironicamente, o fortalecimento do Estado fez com que, aos poucos, a corporação de mercadores e, por conseguinte, o ius mercatorum, perdesse sua influência, o que limitou em muito as transações comerciais.

Uma série de fatores (econômicos, sociais, religiosos), somados aos avanços da ciência, levou, entretanto, ao transbordamento comercial no século XX, resultado daquilo que se tem denominado como globalização. Os desafios da globalização trouxeram consigo a ideia de uma nova lex mercatoria que configuraria um

49 CRUZ, Paulo Marcio. Da Soberania a Transnacionalidade: Democracia, Direito e Estado no Século XXI. Itajaí, UNIVALI Editora, 2011, p. 16, 21.

50 Segue-se aqui o pressuposto defendido por PASOLD, Cesar Luiz, de que "o Estado Contemporâneo - qualquer que seja o suporte ideológico que o sustente - deve possuir uma característica peculiar que é a sua Função Social, expressa no compromisso (dever de agir) e na atuação (agir) em favor de toda a Sociedade" (criadora e mantenedora do Estado). In PASOLD, Cesar Luiz. Função Social do Estado Contemporâneo. 3. ed. rev. atual. amp. Florianópolis: OAB/SC Editora co-edição Editora Diploma Legal. 2003, p. 21. 
ordenamento jurídico supranacional destinado a regular as relações comerciais internacionais, independentemente de fronteiras acima das regras limitadoras estabelecidas pelos Estados-nações.

Não obstante a idealização de um sistema de normas transnacionais que possam reger adequadamente e de forma uniforme o comércio internacional, o comércio transfronteiriço não pode se tornar num reino exclusivo dos mercados internacionais, cenário inaceitável para a formulação de um direito científico e democrático, apto para reger uma sociedade cada vez mais globalizada e em acelerada transformação.

Antes de representar uma supressão de fronteiras, um comércio totalmente desvinculado das leis nacionais, significa um comércio sem barreiras políticas e um direito de mercado emanado apenas por regras autogeradas, certamente há de ignorar qualquer razão que não seja de mercado, despido de preocupação ou restrição de caráter jurídico ou político.

Neste quadro, desconsideram-se as peculiaridades políticas e econômicas de cada grupo nacional, seu estágio de desenvolvimento, suas possibilidades e deficiências, e ficam em evidência apenas objetivos econômicos e financeiros, sem considerar os interesses nacionais, macroeconômicos, que devem ser protegidos, tornando-se campo aberto para a especulação financeira internacional.

Malgrado as acaloradas discussões acerca da aceitação de uma nova lex mercatoria existente em diversas áreas do comércio internacional e aplicada principalmente no campo da arbitragem, a análise mais precisa de forma técnicojurídica leva a crer que não se pode aceitar como sendo objetivo um direito (e uma jurisdição como a arbitragem) orientado exclusivamente pelas frias regras do mercado, desatento às particularidades políticas e econômicas que o comércio internacional reflete, muito especialmente no tocante às desigualdades econômicas entre as nações.

A análise técnico-jurídica dos requisitos para configuração de um sistema jurídico leva à constatação de que a lex mercatoria não preenche os pressupostos para compor um direito supranacional e leva à necessidade da formação de um 
ordenamento supranacional que observe as práticas de um direito transnacional que respeite o principio democrático e que possam se dispor a diminuir as desigualdades sociais, nos moldes de um Direito Transnacional defendido por autores como Cruz, Stelzer, Bodnar, Oliviero ${ }^{51}$, entre outros.

Entretanto, a constatação de que a lex mercatoria não alcança os contornos de um direito supranacional autônomo e autocontido não é suficiente para decretar o fracasso das tentativas de uniformização das regras jurídicas para o comércio extrafronteira.

As reflexões aqui tecidas são na verdade um incentivo à reflexão sobre um direito transnacional do comércio com a participação na construção democrática de todos os agentes nele interessados, como a comunidade internacional, representada por órgãos transnacionais e Estados-nações, juntamente com a classe comercial, libertando a lex mercatoria do estigma de regras contidas apenas por um órgão de classe e servindo como suplemento essencial ao seu completo funcionamento.

\section{REFERÊNCIAS}

BONELL, Michael Joachim. Lex mercatoria. Digesto Discipline Privatistiche. Sezione Commerciale IX. Torino: UTET, 1993.

CATALAN, Marcos Jorge; BUSSATTA, Eduardo Luiz. A Lex Mercatoria. Revista Jurídica Consulex, Ano VII, n. 166, 2003.

COSTA, Judith Martins. Os Princípios Informadores do Contrato de Compra e Venda Internacional na Convenção de Viena de 1980. Universidade Federal Fluminense. Disponível em: <http://www.uff.br/cisgbrasil/ costa.html\#top>. Acesso em: 22 de março de 2014.

CRUZ, Paulo Marcio. Da Soberania a Transnacionalidade: Democracia, Direito e Estado no Século XXI. Itajaí, UNIVALI Editora, 2011.

GOLDMAN, Berthold. Les frontières du droit et lex mercatoria. Archives de Philosophie du Droit. n. 9, 1964.

51 Veja-se, para tanto, obras como: CRUZ, Paulo Márcio e STELZER, Joana (orgs.). Direito e transnacionalidade. 1. ed., 2. reimpr. Curitiba: Juruá, 2011; CRUZ, Paulo Márcio e BODNAR, Zenildo. A Transnacionalidade e a emergência do Estado e do Direito Transnacionais. Itajaí, 2009; OLIVIERO, Maurizio; CRUZ, Paulo Márcio. Reflexões sobre o Direito Transnacional. Novos Estudos Jurídicos, Itajaí, v. 17, n.1, p. 18-28, 2012. Disponível em: <http://siaiweb06.univali.br/seer/index.php/nej/article/view/3635>. 
GUERREIRO, José Alexandre Tavares. Fundamentos da arbitragem do comércio internacional. São Paulo: Saraiva, 1993.

HUCK, Hermes Marcelo. Sentença estrangeira e “Lex Mercatoria": horizontes do comércio internacional. São Paulo: Saraiva, 1994.

KAHN, Philipe. Lex mercatoria et pratique des contrats internationaux: I'expérience français. In Le Contrat Économique International. Bruxelles-Paris, 1975.

KASSIS, Antoine. Problèmes de Base de l'Arbitrage en Droit Comparé et en Droit International. Paris: LGDI, 1987.

LAGARDE, Paul. Approche Critique de la Lex Mercatoria. In Le droits dês relations èconomiques internationais. Études offertes à Berthold Goldman. Paris: Librairies Techniques, 1987.

LANDO, Ole. The Law Applicable to the Merits of the Dispute. Essays on International Commercial Arbitration. London: Petar Sarcevic, Graham \& Trotman/Martins Mijhoff, 1989.

PASOLD, Cesar Luiz. Metodologia da Pesquisa Jurídica: Teoria e Prática. 12. ed. rev. São Paulo: Conceito Editorial, 2011.

Função Social do Estado Contemporâneo. 3. ed. rev. atual. amp. Florianópolis: OAB/ SC Editora coedição Editora Diploma Legal. 2003.

PINHEIRO, Luís de Lima. Direito Comercial Internacional - O Direito Privado da Globalização Econômica. Lisboa: Colibri, 2005.

SANTOS, Boaventura de Sousa (Org.). Globalização: Fatalidade ou Utopia? 3. ed. Porto: Afrontamento, 2005.

STOECKER, C. W. The Lex Mercatoria: to what extent does it exist. Journal of International Arbitration, Vol. 7, n. 1, 1990.

STRENGER, Irineu. Direito do Comércio Internacional e Lex Mercatoria. São Paulo: LTR, 2009.

TOMAZ, Roberto Epifanio. Governança Transnacional. Revista do Direito, UNISC, Santa Cruz do Sul/RG, n. 40, Agosto/Outubro, 142-163, 2013. Disponível em: <http://www. http://online. unisc.br/seer/index.php/direito/article/ view/3710/2887>. Acesso em: 22 de março de 2014. 